\title{
Use of Refractive Index to Monitor Changes in Sugar Content of Stored Sweetpotatoes
}

\author{
William M. Walter, Jr. \\ U.S. Department of Agriculture, Agricultural Research Service, North \\ Carolina Agricultural Research Service, Department of Food Science, \\ North Carolina State University, Raleigh, NC 27695-7624
}

Additional index words. postharvest, liquid chromatography, Ipomoea batatas

\begin{abstract}
The sugar content of five sweetpotato [Ipomoea batatas (L.) Lam.] cultivars ('Centennial', 'Cordner', 'Georgia Red', 'Jewel', and 'Sweet Red') was measured by high-performance liquid chromatography (HPLC) and compared to the sugar content of the cellular sap measured by refractive index (RI). The HPLC and RI sugar contents were measured at harvest, after curing, and during storage. Changes in the sugar content, as determined by the RI, were found to be linearly related to changes in the sugar content of cell sap and tissue, as measured by HPLC, indicating that this method can be used to monitor changes in postharvest total sugar content.
\end{abstract}

The organoleptic quality of cooked sweetpotatoes partially depends on the sugar content of the raw root, because the sugars present in raw roots (sucrose, fructose, and glucose) are sweeter on a weight basis than is maltose (Moskowitz, 1970). Maltose, although not detected in raw roots, is formed during cooking and is usually the most abundant sugar in cooked sweetpotatoes (Picha, 1985). Sucrose, the most abundant sugar in raw roots, is about three times sweeter than maltose; fructose and glucose are, respectively, 5-fold and 2-fold sweeter than maltose (Moskowitz, 1970). However, Koehler and Kays (1991) reported that in a sweetpotato puree model system, sensory panelists consistently ranked sugars in the following order of preference: maltose $\geq$ sucrose $\geq$ fructose. They also found that the optimum preferred sweetness was attained when either maltose or fructose concentration was adjusted to $35 \%$ (by weight). Although maltose is a more important contributor to perceived sweetness than is predicted by the sweetness scale of Moskowitz (1970), sucrose, glucose, and fructose play a significant role in perceived sweetness. Depending on the cultivar, sucrose, fructose, and glucose can account for as much as one-half of the perceived sweetness of a cooked sweetpotato.

Received for publication 9 Aug. 1991. Accepted for publication 2 Dec. 1991. This paper was prepared by a U.S. Government employee as part of his official duties and legally cannot be copyrighted. I express my appreciation to W.W. Collins, Dept. of Horticultural Science, North Carolina State Univ., for providing 'Cordner', 'Georgia Red', and 'Sweet Red'. Mention of a trademark or proprietary product does not constitute a guarantee or warranty of this product by the U.S. Dept. of Agriculture or North Carolina Agricultural Research Service, nor does it imply approval to the exclusion of other products that may be suitable. The cost of publishing this paper was defrayed in part by the payment of page charges. Under postal regulations, this paper therefore must be hereby marked advertisement solely to indicate this fact.
In general, the sugar content of sweetpotatoes increases during curing (Edmond, 1971; Picha, 1987; Walter and Hoover, 1984). During storage, after curing, sugar concentrations vary with storage conditions and length of storage, depending on the cultivar. In a study using six cultivars, Picha (1985) reported that sucrose was higher in baked than in raw roots and that glucose and fructose concentrations increased in baked roots of some cultivars but not in others. Current marketing practices do not employ any measure of organoleptic quality, except whether or not the roots have been cured. In the early part of the season this is, at best, an approximation and, at worst, a guess because sugars are formed at different rates, depending on the cultivar and pre- and postharvest environmental factors. Perceived sweetness is such an important part of consumer acceptance of sweetpotatoes that it would be advantageous to the shipper or processor to have a partial estimate of organoleptic quality, which could be provided by a knowledge of the rate of sugar formation. In some cases, roots would be marketed immediately after curing, while in others storage after curing would be advisable. For this reason, I ascertained if the refractive index (RI) of juice expressed from sweetpotatoes could serve as an indicator of postharvest changes in sugar content.

All cultivars were grown in experimental plots and harvested 120 to 130 days after transplant. 'Centennial' and 'Jewel' were grown in 1987; 'Cordner', 'Georgia Red', and 'Sweet Red' were grown in 1988. Four $22.6-\mathrm{kg}$ containers of each cultivar were brought to the laboratory immediately after harvest. After removal of samples for at-harvest analysis, two boxes were cured for 7 days at $90 \%$ to $95 \%$ relative humidity $(\mathrm{RH})$ and $29.5 \mathrm{C}$. The other two boxes were placed in storage at $14.5 \mathrm{C}$ and $85 \% \mathrm{RH}$ immediately after harvest. After curing, the roots were transferred to the same storage facility that held the uncured roots. Sampling was 

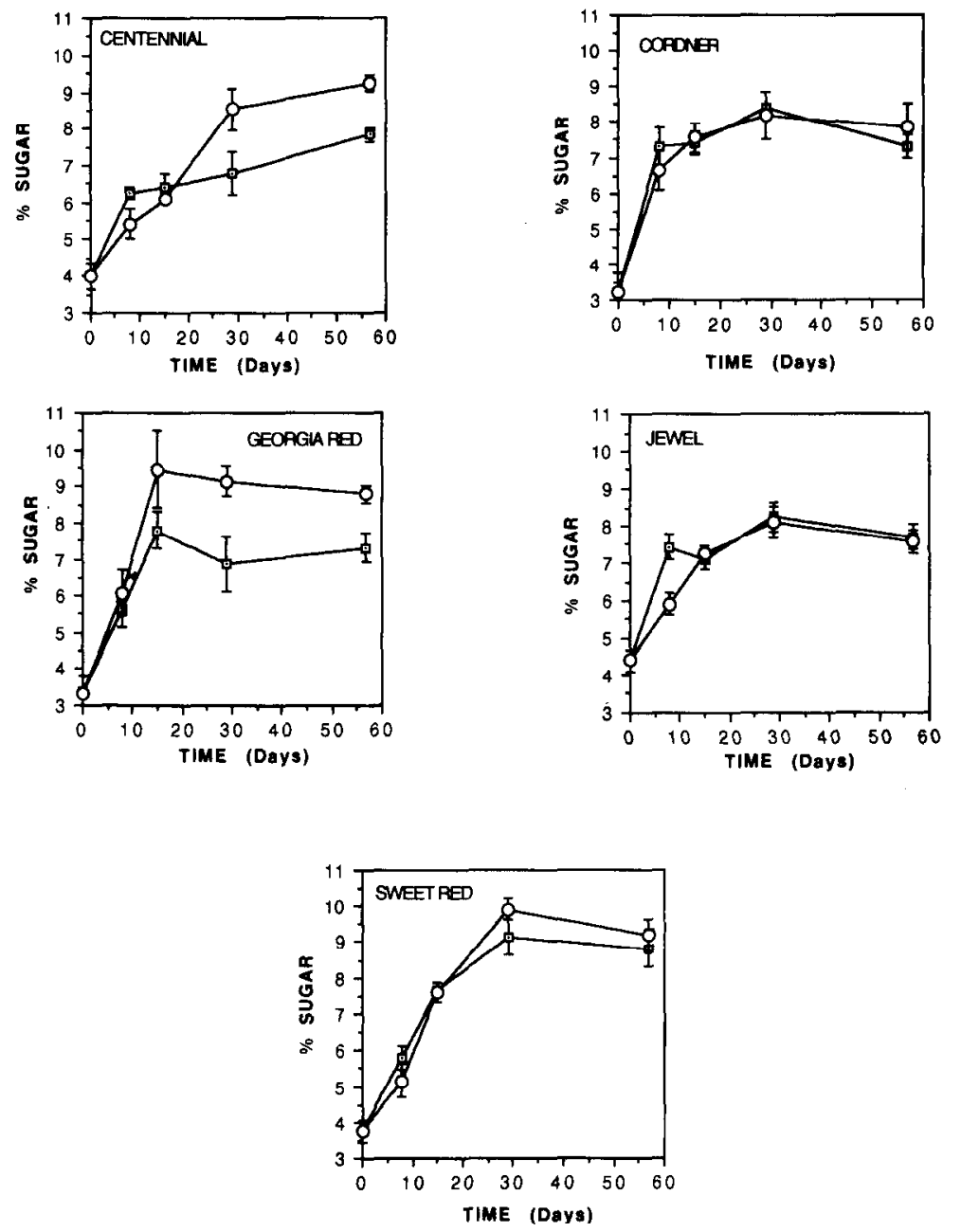

Fig. 1, Tissue sugar content of cured and uncured 'Centennial', 'Cordner', 'Georgia Red', 'Jewel', and 'Sweet Red' sweetpotatoes measured by high-performance liquid chromatography expressed as percent sugar (weight of total sugars/volume of tissue water x 100). Each point is the mean of four replicates $(n=4)$ with vertical bars representing \pm SD. $(-0-)$ cured tissue, $(-O-)$ uncured

done on four replicate samples containing three roots per replicate. Samples were taken for analysis at harvest and at 8, 15, 29, and 57 days after harvest.

For analysis, roots were peeled by hand and cut into quarters (lengthwise). One quarter from each of three roots comprised a sample. The sample was grated and the grated material thoroughly mixed. Portions $(10 \mathrm{~g})$ of the grated samples were dried at $60 \mathrm{C}$ for 2.5 days and then at $100 \mathrm{C}$ for $7 \mathrm{~h}$, and the moisture content was calculated. To measure the juice sugar content, 25-g portions of the grated sample were weighed into cheesecloth and the juice collected by manually compressing the cheesecloth and contents. One milliliter of juice was centrifuged, and the RI was measured on an Abbe-3L refractometer ( $\pm 0.03 \%$ in $0 \%$ to $85 \%$ total solids range) (Bausch and Lomb, Rochester, N.Y.). The sugar content, corrected for temperature, was calculated from a sucrose concentration-RI table (CRC, 1973). A portion $(0.2 \mathrm{ml})$ of the centrifuged juice was mixed with $0.8 \mathrm{ml}$ of $100 \%$ ethanol and stored at $-10 \mathrm{C}$ until analyzed by high-performance liquid chromatography (HPLC).
To measure the total sugar content of the tissue, 5-g portions of the grated material were mixed with ethanol and water and homogenized with a Tekmar Tissuemizer (Tekmar, Cincinnati) for $1 \mathrm{~min}$ at $70 \%$ of maximum speed. The mixture was transferred to a $100-\mathrm{ml}$ volumetric flask and diluted to the mark. Ethanol and water quantities were calculated so that the final ethanol content was $\approx 80 \%$ (assuming the sweetpotato moisture content was 75\%). The mixture was held $\geq 7$ days before analysis to allow attainment of equilibrium. The sugar content of the juice and total sugar content of the tissue were measured by HPLC. The HPLC system was a Waters 6000A pump (Waters, Milford, Mass.), a Waters 410 refractive index detector, a Rheodyne 7125 injector (Rheodyne, Cotati, Calif.), and a Bio-Rad Amino-5S column (Bio-Rad Laboratories, Richmond, Calif.) ( $4 \mathrm{~mm}$ id. $\times 25 \mathrm{~mm}$ in length). The mobile phase was 70 acetonitrile :30 water (v/v), and the flow rate was $1.0 \mathrm{ml} \cdot \mathrm{min}^{-1}$. Quantitation of the sugars was accomplished with a Shimadzu C-R3A integrator (Shimadzu Scientific Instruments, Columbia, Md.). Each replicate was ana- lyzed in duplicate.

The HPLC sugar content of juice and tissue was obtained by summation of sucrose, fructose, and glucose amounts from each chromatogram. Juice sugar content was expressed as weight of sugar per $100 \mathrm{ml}$ of juice. Tissue sugar was converted to weight of sugar per $100 \mathrm{ml}$ tissue water using the moisture content.

Data were tested by analysis of variance or regression using the General Linear Model procedure of SAS (SAS Institute, 1985). Regression analysis was performed on pooled data from cured and uncured roots.

At all sampling dates, tissue sugar content was higher than the juice sugar content, indicating that the sugars were not equally distributed throughout the tissue. Since the sugar content of the juice and tissue for all cultivars changed in a similar fashion during this study, this part of the discussion is limited to tissue sugar content. Sucrose was the major sugar in all cultivars, while glucose and fructose were present in lower amounts (data not shown). Maltose was not detectable. This pattern of sugar composition has been reported previously for sweetpotatoes (Picha, 1987; Walter and Hoover, 1984). For all cultivars, the tissue sugar content increased during the first 8 days after harvest, whether cured or uncured, and, with the exception of 'Georgia Red', continued to increase for 29 days after harvest (Fig. 1). After 29 days, with the exception of 'Centennial', the sugar content either remained unchanged or declined. The effect of curing on total sugar content was variable. Curing did not cause dramatic increases in sugar content as compared to the uncured roots. After 8 days, the sugar content of cured roots was higher than that for uncured roots only in 'Centennial' and 'Jewel' (Fig. 1). After the curing period had ended, the sugar content of roots from both treatments tended to converge. For 'Centennial' and 'Georgia Red' on the last two sampling dates, the uncured root sugar content was higher than that of cured roots. For the other cultivars, no differences were observed between cured and uncured roots.

I found that sugar content, as measured by RI, was linearly related to total sugar content of juice and tissue as determined by HPLC (Fig. 2). For the cultivars Centennial, Cordner, Georgia Red, and Sweet Red, the equations describing the linear relationship between RI sugar content and total sugar content in juice and tissue accounted for $83 \%$ to $93 \%$ of the variability. For 'Jewel', the equation describing the relationship between HPLC sugar content in juice and RI sugar content accounted for only $68 \%$ of the variability. However, the regression equation for HPLC sugar content in 'Jewel' tissue vs. RI sugar content accounted for $91 \%$ of the variability. The regression equations for the juice showed that the $\mathrm{Y}$ intercept ranged from a high of 6.4 for 'Centennial' to a low of 3.9 for 'Cordner'. These values are indicators of the amount of nonsugar solute present in the juice.

Results from this study indicate that changes in the postharvest sugar content of the sweetpotato cultivars used in this study can be 

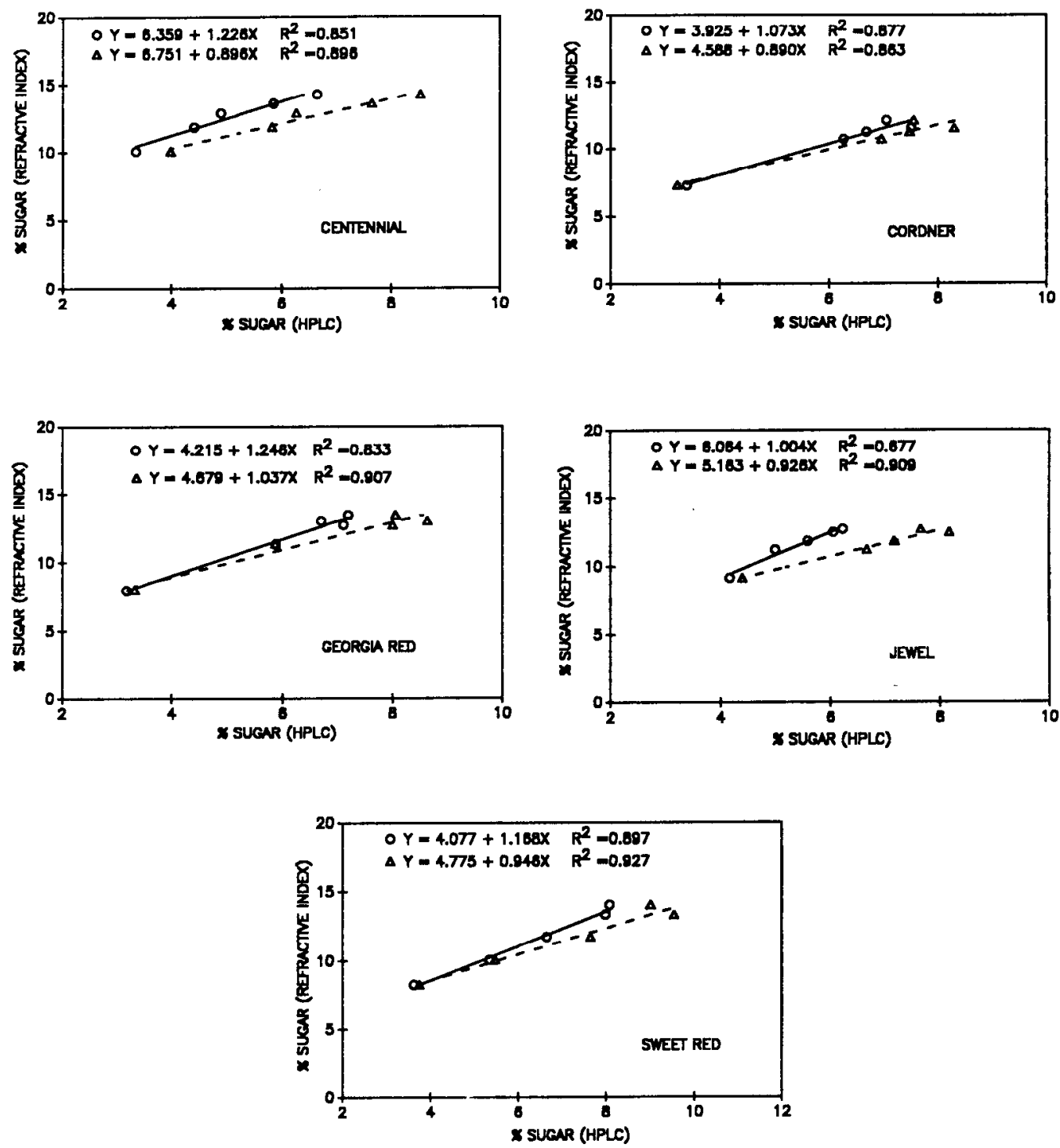

Fig. 2. Regression of percent sugar (weight of total sugars/volume) measured by juice refractive index on percent sugar measured by high-performance liquid chromatography for juice (-0-) and tissue $(-\Delta-)$ of 'Centennial', 'Cordner', 'Georgia Red', 'Jewel', and 'Sweet Red' sweetpotatoes. Each point is the mean of four replicates each for cured and uncured tissue $(n=8)$. Codes for the regression equations are: $\mathrm{O} Y=$ juice and $\Delta \mathrm{Y}=$ tissue.

followed using the RI of the juice. Although we used a laboratory refractometer in this study, a less expensive hand-held unit would provide sufficient accuracy and could be used for field applications. Thus, a shipper or processor could monitor the changes in sugar content and base disposition and/or processing decision on the results. This procedure would be of use in the early portion of the postharvest period while sugar content is rapidly changing.

\section{Literature Cited}

Edmond, J.B. 1971. Marketing the fresh product, p. 247-263. In: J.B. Edmond and G.R. Ammerman (eds.). Sweet potatoes: Production, processing, and marketing. AVI, Westport Conn.

Koehler, P.E. and S.J. Kays. 1991. Sweetpotato flavor: Quantitative and qualitative assessment of optimum sweetness. J. Food Quality 14:241249.

Moskowitz, H.R. 1970. Ratio scales of sugar sweetness. Perception Psychophysics 7:315-321.

Picha, D.H. 1985. HPLC determination of sugars in raw and baked sweet potatoes. J. Food Sci. 50:1189-1190, , 1210.

Picha, D.H. 1987. Carbohydrate changes in sweetpotatoes during curing and storage. J. Amer. Soc. Hort. Sci. 112:89-92.

SAS Institute. 1985. SAS user's guide: Statistics, version 5 (ed.). SAS Institute, Cary, N.C.

Walter, W. M., Jr., and M.W. Hoover. 1984. Effect of pre-processing storage conditions on the composition, microstructure, and acceptance of sweetpotato patties. J. Food Sci. 49:1258-1261.

Weast, R.C. 1973. CRC handbook of chemistry and physics. CRC Press, Cleveland. p. E233. 